HELENE YBRANDT ${ }^{*} \&$ KERSTIN ARMELIUS

\title{
ADOLESCENTS' MENTAL HEALTH AND THEIR IMAGES OF SELF AND PARENTS
}

(Received: 25 March 2009; accepted: 19 October 2009)

\begin{abstract}
The relation between images of self and parents as defined in interpersonal theory and by the Structural Analysis of Social Behaviour (Benjamin), and internalising and externalising problems, as defined by the Youth Self-Report (Achenbach) was studied in a sample of 199 nonclinical adolescents (92 boys and 107 girls) aged between 13 and 17 years. Regression analyses showed that the pattern relating images of self and parents to mental health problems was different for boys and girls. Internalising problems for girls were best predicted from aspects of their self-image while for boys parental behaviour played a larger role. A pattern of self-blame and lower self-affirmation together with parental blame was important for girls' externalising problems and a pattern of self-neglect and low self-autonomy and an uncertainty of parental love were important for boys externalising problems. Results emphasise that boys and girls have different kinds of vulnerabilities as risk factors for mental health problems.
\end{abstract}

Keywords: adolescence, mental health, image of self, image of parents, SASB, YSR

Mentalhygiene, Selbstbild und Elternbild bei Teenagern: Untersucht wurden das mittels der interpersonalen Theorie und der Strukturanalyse sozialen Verhaltens (Structural Analysis of Social Behavior; SASB; Benjamin) bestimmte Selbstbild und das Elternbild sowie der mittels der Achenbach-Skala zur Selbstbeurteilung (Youth Self-Report; YSR) bestimmte Zusammenhang zwischen Internalisierungs- und Externalisierungsproblemen anhand einer Stichprobe von 199 (92 Jungen, 107 Mädchen) 13 bis 17 Jahre alten klinisch nicht auffälligen Teenagern. Die Regressionsanalysen zeigten, dass es bezüglich des Zusammenhangs von Selbst- und Elternbild mit mentalhygienischen Problemen Unterschiede zwischen Mädchen und Jungen gibt. Internalisierungsprobleme ließen sich bei Mädchen am ehesten aufgrund einzelner Aspekte des Selbstbildes vorhersagen, während bei den Jungen das Verhalten der Eltern eine größere

${ }^{*}$ Corresponding author: Helene Ybrandt, Department of Psychology, Umeå University, Mediagränd 14, D-114 SE-90187 Umeå, Sweden; Helene.Ybrandt@psy.umu.se. 
Rolle spielte. Bei den Externalisierungsproblemen waren bei den Mädchen die Faktoren Selbstbeschuldigung, unterdurchschnittliche Selbstbejahung und Beschuldigung der Eltern von großem Einfluss, während bei den Jungen Selbstvernachlässigung, niedrige Selbstautonomie und unsichere elterliche Zuneigung besonders bedeutend waren. Die Ergebnisse machen deutlich, dass die Verletzlichkeit von Jungen und von Mädchen vom Gesichtspunkt mentalhygienischer Probleme her unterschiedliche Risikofaktoren darstellen.

Schlüsselbegriffe: Pubertät, Metalhygiene, Selbstbild, Elternbild, YSR

It is often suggested that a negative and vulnerable self-concept may contribute to adolescents' dysfunction, as shown in the externalising and internalising of problems. For example, a negative self-concept is associated with externalising problems, manifested in aggressive behaviour (MARSH et al. 2001; MORETTI et al. 2001) and in antisocial and criminal behaviour (HAY 2000; WELZENIS 1997), and with internalising problems, manifested in depression and suicidal ideation (ERKOLAHTI et al. 2003; ORBACH et al. 1998) and in eating problems (HUMPHREY 1989; WONDERLICH et al. 1996). On the other hand, a positive self-concept is seen as important for general wellbeing and positive development (MCCULLOUGH et al. 2000). However, the findings of research on the relation between adolescent self-concept and mental health are not explicitly formulated in terms of which aspects of this concept produce different mental health symptoms in adolescence.

Both theoretically and psychometrically, there is an acceptance of multidimensionality with respect to the self-concept (BUTLER \& GASSON 2005; HARTER et al. 1997) and as pointed out by MARSH et al. (2004) a multidimensional approach to research will give a more complete understanding of the self-concept and also have important implications for interventions. The aim of this study is thus to use a multidimensional perspective to explore the influence of the self-concept (self-image and image of parents) on both externalising and internalising symptoms.

According to developmental theories (e.g. BOWLBY 1988; STERN 1985), the selfconcept is developed, built and organised by a process of internalisation of interpersonal relationships. Early experiences of positive parental behaviour are therefore most important for achieving a positive self-concept that leads to mental health and positive development. It is well established that early parental behaviour that is perceived as positive is related to a more positive self-concept (ÖSTGÅRD-YBRANDT \& ARMELIUS 2004) and that parental behaviour perceived as negative in terms of a low level of emotional warmth is related to adolescents' problem behaviours such as anxiety, depression, and delinquency (e.g. HUDSON \& RAPEE 2001; MURIS et al. 2003; RUCHKIN et al. 2001; SIQUELAND et al. 1996; WENAR \& KERIG 2000). These results agree on the importance of warmth and acceptance by parents.

However, the influence of parental control and of their granting of autonomy is still being debated. Both constructs are complex and they have often been treated as opposite ends of the same construct. SILK et al. (2003) suggest that parental granting of autonomy and parental control should be treated as distinct constructs. The absence of parental control does not necessarily imply that parents have granted an adolescent autonomy. Behavioural control from parents seems to be related to fewer externalised 
problems and better adjustment (STEINBERG et al. 2006). However, research also shows that overprotection from parents, implying too much control, is associated with more mental symptoms (MURIS et al. 2003) and with more aggression (ALUJA et al. 2005). Also, as pointed out by ROELOFS et al. (2006), parental control and overprotection and the absence of autonomy promotion from parents may predict mental problems in youth. Granting of autonomy has been less studied but findings indicate that autonomy granting is related to better adjustment in adolescents (STEINBERG 2000). Autonomy also refers to aspects of self-autonomy. With adolescents a number of different aspects of self-autonomy have been identified. NoOM et al.'s (2001) definitions of attitudinal, emotional, and functional autonomy all share a core of self-governance in an adolescent and these aspects are related to better adjustment.

The Structural Analysis of Social Behaviour (BENJAMIN 1974; 1996) combines the dimensions of emotional warmth and control-autonomy in a multidimensional model that can be used to describe aspects of both the self-image and perception of parental behaviour. With the SASB model it is possible to differentiate specific patterns of the self-image and the image of parents and to assess how these patterns may be related to some of the broad range of psychiatric and behavioural disturbances in adolescence.

Researchers who have used the SASB to study specific dysfunctional patterns in relation to mental health have found, for example, that patterns of blaming parents are related to a tendency to self-blame expressed in eating problems like bulimia (WONDERLICH et al. 1996). It has also been found that a deviant self-image and deviant perceptions of parents are related in borderline and psychotic personality disorders (ARMELIUS \& GRANBERG 2000) and that self-neglect and parental neglect are found in girls with antisocial behaviour problems expressed in aggression and criminality (ÖsTGÅRD-YBRANDT \& ARMELIUS 2004).

The theoretical roots of the SASB model lie in interpersonal and attachment theory (FLORSHEIM et al. 1996). According to these theories, and also found in SASB research, percepts of positive important others constitute positive working models that are developed before adolescence, and the self-image seems to be stable in normal adolescence (ADAMSON \& LYXELL 1996; ÖSTGÅRD-YBRANDT \& ARMELIUS 2004). A negative self-image and pathological and dysfunctional behaviour are understood to result from the effect of deviant early relationships on the normal processes of relating.

The SASB model has three different focuses: the transitive focus describes behaviour directed towards others; the intransitive focus describes reactions to others; and the self-image describes introjected behaviour directed toward the self or the selfimage. For each focus, the two dimensions of affiliation (positive - negative) and interdependence (control - autonomy) are combined in a circumplex structure. The full model has 36 points, which in the cluster version of the model are reduced to eight clusters of affiliations and control (see Figure 1). 


$\begin{array}{cccc} & \begin{array}{l}\text { (1) Autonomy } \\ \text { Self-Autonomy }\end{array} & \\ \text { (8) Neglect } & \mathbf{I} & \text { (2) Affirm } & \\ \text { Self-Neglect } & \mathbf{I} & \text { Self-Affirm } & \\ & \mathbf{I} & & \text { (3) Love } \\ \text { (7) Rejection } & \mathbf{I} & & \text { Self-Love } \\ \text { Self-Attack } & \mathbf{1} & \text { (4) Protect } \\ \text { (6) Blame } & \text { Self-Protect }\end{array}$

(5) Control

Self-Control

Affiliation axis

Interdependence axis

Figure 1

The Structural Analysis of Social Behaviour (SASB): Cluster version. Parental behaviour with roman letters and the self-image with italic letters (BENJAMIN 1993)

According to the SASB model, normal development has a baseline in the positive clusters (in the model described, in clusters 2, 3, and 4) with a balance between control (cluster 5) and autonomy (cluster 1). Pathological development is indicated by any deviation from that pattern (behaviours located mainly in clusters 6,7 , and 8) (BENJAMIN 1993; FLORSHEIM et al. 1996).

The purpose of the present investigation was to examine how the self-concept, defined as the self-image and images of early parental behaviour measured with the SASB model, is related to externalising and internalising problems (behavioural and emotional problems), as measured by the Youth Self-Report (ACHENBACH 1991) in a group of normal adolescents. The hypothesis of separation-individuation states that with age the importance of parental support for emotional adjustment decreases while the own identity plays a more important role (see e.g. MeEus et al. 2005 for a discussion). Therefore it seems reasonable to expect that during adolescence internalised patterns of behaviour towards self or aspects of the self-image should be more important for mental health compared with images of early parental behaviour. Generally, negative aspects of the self-image and images of parents were expected to be associated with more behavioural and emotional problems. The following hypotheses were explored: 
- internalising problems, which indicate that problems are directed inwards towards self, were expected to be related only to aspects of the self-image, while for externalising problems, where problems are acted out, images of parents should also be important.

- self-autonomy and parental autonomy granting were expected to be related to fewer behavioural and emotional problems.

As previous research is contradictory, we had no specific hypothesis about the relation between parental control and externalising and internalising problems. Gender differences in these relationships were also analysed but due to the exploratory nature of these comparisons no specific hypotheses were formulated. It is well known that girls and boys differ in internalising and externalising problems (VERHULST et al. 2003) and that gender may have a great impact on how adolescents perceive some aspects of themselves such as physical appearance, self-esteem, and emotional stability (MARSH et al. 2004). However, differences in terms of positive and negative selfimage and image of early upbringing seem to be small in normal adolescent development (ÖSTGÅRD-YBRANDT \& ARMELIUS 2004). Even if mean levels of self-concept and behavioural and emotional problems differ between boys and girls, the pattern relating aspects of the self-concept to behavioural and emotional problems may be the same and this has also been found in empirical studies (MARSH et al. 2004; MURIS et al. 2003; ANDERSEN et al. 2007).

\section{Method}

\subsection{Participants}

The participants in this study were a group of non-clinical adolescents enrolled in a research project that set out to survey the mental health and social context of adolescents with psychiatric and antisocial problems (ARMELIUS \& HÄGGLÖF 1998). The sample was obtained using a clustered sampling procedure with school classes (four middle and junior high schools and one high school) in a small town in the north of Sweden (105,000 inhabitants). To obtain a representative distribution with respect to socioeconomic factors, subjects were drawn from schools in different socioeconomic areas and from vocational and academic classes in high schools. The participants were 199 Caucasian adolescents (92 boys and 107 girls) ranging in age from 13 to 17 years $(\mathrm{M}=15.1 ; \mathrm{SD}=1.4)$. The majority $(69 \%)$ lived with both their parents, and $23 \%$ lived with a single parent. Comparison of the figures in regard to living arrangements with the official statistics for the population of Sweden indicates that our sample was representative in this regard (Statistics Sweden 2001). 


\subsection{Procedure}

Participation in the study required adolescent and parental consent and anonymity and confidentiality were guaranteed. Classroom teachers administered the self-rating questionnaires to the students as part of a battery of questionnaires about self-concept, parental relationships, and externalising and internalising problems. Each participant was given a cinema ticket as a gratuity. The attrition rate of $33 \%$ (boys $40 \%$; girls $26 \%$ ) includes adolescents who were absent from school and those who chose not to participate or did not get parental consent and attrition rate did not differ among schools. The study was approved by the ethics committee.

\section{Instruments}

\subsection{Structural Analysis of Social Behaviour (SASB)}

Self-image was measured using the Swedish version of the SASB (BENJAMIN 1974) with 36 statements that describe different combinations of affiliation and control combined into eight clusters. Cluster 1 has five statements that express perceptions of self as being autonomous and free, cluster 2 has four statements that express self-affirmation and self-exploration, cluster 3 has five statements that express self-love and selfjoy, cluster 4 has four statements that express self-care and self-protection, cluster 5 at the opposite pole to cluster 1 has five statements that express self-control and self-restraint, cluster 6, like the other clusters on the left-hand side of the model, is about negative behaviour towards self and has four statements that express self-blame and putting self down, cluster 7 has five statements that express self-hate and self-destruction, and cluster 8 has four statements that express self-neglect and self-recklessness.

Early parental behaviour was assessed using the short form of the SASB questionnaire (BENJAMIN 1987) with 32 statements about parental behaviour. Cluster 1 deals with granting autonomy, cluster 2 deals with affirmation, cluster 3 deals with love, cluster 4 deals with support, cluster 5 , at the opposite pole to cluster 1 , deals with control, cluster 6 deals with blaming, cluster 7 deals with rejection, and cluster 8 deals with neglect.

Participants were instructed to rate how well each statement describes their perception of their own behaviour against themselves and the behaviour of their parents towards them when they were 5-10 years of age. The period is chosen for the child has become cognitive-aware of the upbringing and the period is just before adolescence which gives the data actuality. The rating scale was between 0 (does not agree) to 100 (perfect agreement). PINCUS et al. (1998) evaluated the structural validity of the SASB and its two-dimensional factorial structure. They found that the criterion of reducibility was met as regards the two dimensions of affiliation and interdependence. Test - retest reliability for the SASB is $r=0.87$ for the American version (36 statements) (BENJAMIN 1987). Internal consistency for the Swedish version is around 0.80. As regards construct validity, factor analysis shows that the Swedish translation is 
consistent with the model. ${ }^{1}$ The psychometric properties for the internal consistency of the scales in the short-form version (parental actions) are appropriate $\alpha \mathrm{s}>0.70$ (BENJAMIN 1987; ÖSTGÅRD-YBRANDT \& ARMELIUS 2004).

\subsection{Youth Self-Report (YSR)}

The Youth Self-Report provides self-ratings for 112 problem items for ages 6 to 18 (ACHENBACH 1991). Youths rate themselves for how true each item is now or was within the past six months, using a three-point Likert scale. The subtests are Withdrawn (shy, alone, reserved); Somatic Complaints (nausea, aches, headaches); Anxious/Depressed (sad, worthless, thinks about killing self); Social Problems (not liked by other kids, teased, acts too young); Thought Problems (strange behaviours, strange ideas, hears things); Attention Problems (trouble concentrating, daydreams, poor school performance, cannot sit still); Delinquent Rule-Breaking Behaviours (steals things at home, hangs around bad kids, lies or cheats); and Aggressive Behaviours (threatens to hurt people, gets into fights, disobedient at school). Confirmatory factor analysis from a study of SoNG et al. (1994) found support for two broadband factors. Somatic Complaints and Anxious/Depressed were reasonably pure measures of the Internalising factor, and Delinquent Behaviours and Aggressive Behaviours were measures of the Externalising factor and these two factors were used to measure behavioural and emotional problems in the present study. The reliability and validity of YSR has been found acceptable and several international studies support the psychometric quality of the instrument (e.g. BELTER et al. 1996; BROBERG et al. 2001; SONG et al. 1994).

\subsection{Statistical Analysis}

A series of step-wise multiple regression analyses were conducted with internalising and externalising problems as dependent variables and different aspects of the selfimage, images of parents, and age as predictors. For the whole group gender was also entered as a predictor. Differences between genders were tested with Student's $t$-test. Analyses were conducted with the SPSS software package, version 15.0. The level of significance was set at $p<0.05$ in all statistical analyses. Tolerance values were used as an indicator of collinearity and they were close to one for all variables.

\footnotetext{
${ }^{1}$ ARMELIUS, K. (2001) 'Reliability and Validity for the Swedish Version of SASB - the Self-Image Test' (Manuscript).
} 


\section{Results}

\subsection{Self-image, images of parents and internalising and externalising problems}

Since comparison between mother and father was not in focus in the study, and to reduce the number of variables, ratings of the eight different kinds of behaviour from mother and father were combined into ratings of parental behaviour. There was only one significant difference between boys and girls where on the YSR, girls were found to have more internalising problems $t(197)=3.15, p<0.002$ than boys. The means and standard deviations for boys and girls for the SASB variables and internalising and externalising problems are shown in Table 1.

Table 1

Means and standard deviations for the self-image and memories of parental behaviour and for internalising and externalising problem scales for girls $(N=107)$ and boys $(N=92)$

\begin{tabular}{lcccc}
\hline \multirow{2}{*}{$\begin{array}{l}\text { SASB and YSR } \\
\text { variables }\end{array}$} & \multicolumn{2}{c}{ Girls } & \multicolumn{2}{c}{ Boys } \\
\hline Self-autonomy & 53.88 & 14.80 & 56.29 & 14.60 \\
Self-affirmation & 72.58 & 20.90 & 73.46 & 20.47 \\
Self-love & 68.86 & 18.04 & 69.72 & 17.53 \\
Self-protection & 60.08 & 15.67 & 60.34 & 15.98 \\
Self-control & 55.71 & 18.49 & 58.16 & 18.95 \\
Self-blame & 22.43 & 20.66 & 18.18 & 17.95 \\
Self-attack & 16.71 & 17.70 & 14.57 & 16.38 \\
Self-neglect & 24.63 & 15.17 & 23.94 & 17.00 \\
Parents grant autonomy & 48.74 & 30.04 & 49.50 & 28.29 \\
Parents affirm & 84.75 & 16.92 & 80.71 & 20.57 \\
Parents love & 77.08 & 21.16 & 70.23 & 28.00 \\
Parents support & 86.30 & 18.59 & 84.70 & 18.18 \\
Parents control & 56.35 & 28.40 & 58.58 & 25.04 \\
Parents blame & 9.14 & 18.67 & 11.38 & 20.56 \\
Parents reject & 6.37 & 16.73 & 5.06 & 12.79 \\
Parents neglect & 4.34 & 12.70 & 7.07 & 16.15 \\
Internalising (YSR) & 11.65 & 8.12 & 8.42 & 7.07 \\
Externalising (YSR) & 13.24 & 6.32 & 14.60 & 9.13 \\
\hline
\end{tabular}


As seen in Table 1, both boys and girls have positive images of themselves and their parents and with a balance in control and autonomy. The YSR ratings show the values that are expected in a normal group of adolescents.

\subsection{Prediction of internalising and externalising problems from the self-concept}

First, two step-wise multiple regression analyses were performed on the whole group of adolescents with internalising and externalising problems as dependent variables and the different aspects of their self-image (eight variables) and their images of parents as independent variables (eight variables). Since a general background in the present study was to relate different aspects of the self-image to internalising and externalising problems and the additional importance of perceived early parental behaviour, the different aspects of the self-image together with age and gender were entered as the first block, and the different aspects of memories of early parental behaviour as the second block. Next separate analyses were done for girls and boys. The results for the whole group are shown in Table 2, and the separate analyses for girls and boys are shown in Tables 3 and 4.

Table 2

Summary of hierarchal regression analyses predicting adolescents' internalising and externalising problems from the self-image and memories of parental behaviour

$(N=199)$

\begin{tabular}{llrccc}
\hline $\begin{array}{l}\text { Problem } \\
\text { scales }\end{array}$ & $\begin{array}{l}\text { Images of self } \\
\text { and parents }\end{array}$ & $B$ & SE B & $\beta$ & Adj $R^{2}$ \\
\hline $\begin{array}{l}\text { Internalising } \\
\text { Step 1 }\end{array}$ & Self-blame & 0.10 & 0.04 & $0.23^{* *}$ & 0.27 \\
& $\begin{array}{l}\text { Self-love } \\
\text { Gender* }\end{array}$ & -0.10 & 0.03 & $-0.25^{* *}$ & 0.32 \\
& Self-neglect & -2.81 & 0.97 & $-0.18^{* *}$ & 0.34 \\
& & 0.08 & 0.04 & $0.16^{*}$ & 0.36 \\
Step 2 & Parental rejection & 0.08 & 0.04 & $0.14^{*}$ & 0.37 \\
Externalising & & & & & \\
Step 1 & Self-neglect & 0.19 & 0.04 & $0.37^{* * *}$ & 0.18 \\
Step 2 & Parental neglect & 0.11 & 0.05 & $0.17^{*}$ & 0.22 \\
& Parental love & -0.05 & 0.02 & $-0.15^{*}$ & 0.24 \\
\hline
\end{tabular}

*Girls are coded as 1. 
As can be seen in Table 2, age did not explain any significant proportion of variance, and gender was significant only for internalising problems where being a girl was associated with more internalising problems. Generally different aspects of the self-image explained most of the variance in both externalising and internalising problems. The strongest relation between behavioural and emotional problems and aspects of the self-image was found for internalising problems with more self-blame and less self-love and more self-neglect related to more problems and perception of hostile parents marginally increased explained variance in internalising problems. Variance in externalising problems was explained from self-neglect but memories of parental behaviour were also important where those kinds of problems were increased by parental neglect and decreased by parental love.

Table 3

Summary of hierarchal regression analyses predicting internalising and externalising problems from the self-image and memories of parental behaviour for girls $(N=107)$

\begin{tabular}{llcccc}
\hline $\begin{array}{l}\text { Problem } \\
\text { scales }\end{array}$ & $\begin{array}{l}\text { Images of self } \\
\text { and parents }\end{array}$ & $B$ & $S E B$ & $\beta$ & Adj $R^{2}$ \\
\hline $\begin{array}{l}\text { Internalising } \\
\text { Step 1 }\end{array}$ & Self-blame & 0.12 & 0.04 & $0.30^{* * *}$ & 0.45 \\
& Self-neglect & 0.10 & 0.05 & $0.18^{* * *}$ & 0.51 \\
& Age & -0.87 & 0.42 & $-0.16^{*}$ & 0.53 \\
Externalising & & & & & \\
Step 1 & Self-affirm & -0.10 & 0.03 & $-0.34^{* *}$ & 0.24 \\
& Self-neglect & 0.12 & 0.05 & $0.26^{*}$ & 0.30 \\
Step 2 & Parental blame & 0.10 & 0.03 & $0.26^{* *}$ & 0.36 \\
& & & & & \\
\hline
\end{tabular}

For girls, internalising problems were strongly related to aspects of the self-image and more self-blame and more self-neglect predicted almost $50 \%$ of the variance in these problems. Age added another $2 \%$ of explained variance and was associated with less internalising problems in girls. Externalising problems for girls showed the strongest relation to lower self-affirmation but also self-neglect predicted variance in externalising problems for girls. In addition, the perception of parental blame predicted externalised problems in girls. 
Table 4

Summary of hierarchal regression analyses predicting internalising and externalising problems from different aspects of the self-image and images of parents for boys $(N=92)$

\begin{tabular}{llcccc}
\hline $\begin{array}{l}\text { Problem } \\
\text { scales }\end{array}$ & $\begin{array}{l}\text { Images of self } \\
\text { and parents }\end{array}$ & $B$ & $S E B$ & $\beta$ & Adj $R^{2}$ \\
\hline $\begin{array}{l}\text { Internalising } \\
\text { Step 1 }\end{array}$ & & & & & \\
& $\begin{array}{l}\text { Self-neglect } \\
\text { Self-autonomy }\end{array}$ & 0.16 & 0.04 & $0.38^{* * *}$ & 0.13 \\
Step 2 & -0.12 & 0.05 & $-0.24^{*}$ & 0.20 \\
& Parental love & -0.12 & 0.03 & $-0.45^{* * *}$ & 0.25 \\
& $\begin{array}{l}\text { Parental support } \\
\text { Parental }\end{array}$ & 0.19 & 0.06 & $0.45^{* *}$ & 0.30 \\
& rejection & 0.17 & 0.07 & $0.29^{* *}$ & 0.36 \\
Externalising & & & & & \\
Step 1 & Self-neglect & 0.18 & 0.06 & $0.32^{* *}$ & 0.16 \\
Step 2 & & & & & \\
& Parental love & -0.08 & 0.03 & $-0.25^{* *}$ & 0.23 \\
& Parental rejection & 0.16 & 0.08 & $0.21^{*}$ & 0.26 \\
\hline
\end{tabular}

For boys, self-neglect was related to both internalising and externalising problems. The self-image dimension of control and autonomy was also associated with internalising problems in boys, with more self-autonomy related to less internalising problems. For both internalising and externalising problems, less parental love and more parental rejection were related to more problems and internalising problems in boys also increased with less parental support.

\section{Discussion}

This paper investigated the relation between different aspects of the self-image and perceptions of early parental behaviour and externalising and internalising problems in a group of normal adolescents. For the whole group there was support for the hypothesis that internalising problems would be explained mainly from different aspects of the self-image, while for externalising problems the images of parents would also be important. However, in the present study this pattern was not the same for boys and girls. Generally girls' behavioural and emotional problems were related to the self- 
image, whereas for boys' their images of parents played a greater role for mental health problems. For girls, the aspects of self-blame and self-affirmation were most important, whereas for boys the aspects of self-neglect and an autonomous self were important. The relation between perceived parental behaviour and externalising and internalising problems also differed between boys and girls. For girls, parental blame was the only aspect of parental behaviour that predicted behavioural and emotional problems. For boys, both internalising and externalising problems were predicted from an uncertainty of parental love and for internalised problems also an uncertainty of parental support.

Perceived self-neglecting behaviour seems to be a risk factor for both externalising and internalising problems in both boys and girls. This pattern was, however, much more pronounced for boys than for girls. High self-neglect in the group of adolescent boys may indicate a lack of self-reflecting behaviour, which may well be an indicator of deviation from normal adolescent development (STEINBERG \& SHEFFIELD MORRIS 2001). Self-neglect may be a sign of a less mature self-image, in which external factors still play an important role in experienced well-being. For example, findings have indicated that perceived parental support has no effect on depression trajectories as adolescents grow older, reflecting the changing role of parents when adolescents begin to establish their own independent lives and have a more stable self-image (MEADOws et al. 2006). The results for boys in the present study, which show that the images of parents played a greater role in behavioural and emotional problems than aspects of the self-image, are in line with an interpretation of a less mature self-image for the boys in the age group used in the present study. A more speculative interpretation of the association between self-neglect and mental health problems in this group of adolescents is that self-neglect, which in the SASB model is a combination of a hostile and autonomous self-image, may be seen as the more negative aspect of selfautonomy defined as detachment (RYAN \& LYNCH 1989).

In addition to self-neglect, the dimension of control-autonomy in the self-image seems to be more important for behavioural and emotional problems in boys than in girls. Generally, it seems that too little autonomy in the self-image is associated with more internalised problems in boys. Theories about gender differences stress that boys are socialised more toward independence and separation/autonomy than girls are (CHODOROW 1978; GILligan 1982). Thus, even if autonomy is an important developmental goal for both boys and girls (NoOM et al. 1999), compared to girls problems in attaining this goal may be more devastating for boys' well-being. Even if highly speculative, our finding that for boys more parental support was associated with an increase in their internalising problems, could be related to this conclusion about boys' vulnerability to a lack of parental encouragement of self-autonomy.

For boys, a risk factor for both internalising and externalising problems seems to be uncertainty of their parents' love as expressed in lower ratings of parental love and higher ratings of parental rejection. A recent study by EBERHART et al. (2006) found that higher levels of depression in boys were explained in part by a stronger association to the experience of a lack of mother's affiliation rather than to self-negativity. Girls showed the opposite pattern, with higher levels of negative self-perceptions re- 
lated to depression. LEADBEATER et al. (1999) concluded that 'addressing excessive dependency concerns in the relationships of depressed boys may be particularly important to their recovery' (p. 1279).

For girls, internalising blame and tendencies to devaluate the self seem to be risk factors for mental health problems. According to interpersonal theory (KIESLER 1996), such a self-image pattern may increase the probability of experiencing blame and devaluation from others, for the self-image constitutes a filter through which an individual views and responds to the behaviour of others. A recent study by ERICKSON \& PINCUS (2005) supports this assumption. They found that anxious young adults had both a more negative self-image and also perceived a brief encounter with a stranger in a more negative way. Generally girls are more vulnerable to negative aspects of relationships than boys. For example, girls worry more than boys about how they are accepted and liked by others (PRINSTEIN et al. 2005) and girls are more stressed by problems in relationships than boys (RUDOLPH \& HAMMEN 1999). Girls' heightened concern about social evaluation has also been found to be related to higher levels of depression (RUDOLPH \& CONLEY 2005). The vulnerability of girls to negative approval from others may also underlie the finding in the present study that for girls the only parental behaviour that predicted behavioural and emotional problems was parental blame.

Some specific limitations of this study should be acknowledged. First, the analyses relied on adolescents' self-reports, some of them retrospective in nature (the report on early parenting). Self-report data are always liable to distortion for motives such as self-protection and self-enhancement (GRAMZOW et al. 2003). They are also sensitive to the adolescents' ability for self-reflection, which may lead to underestimation of self-negativity and internalising and externalising problems in the study. However, this risk has to be balanced against the risk that obtaining reports of adolescents' self-concept and problem behaviours from other informants such as parents and teachers will result in a lack of the unique information that is only available from the adolescents themselves (HOPE et al. 1999).

The attrition in the present study may have influenced the results mainly to decrease correlations due to lower variability in the study variables since usually those who are absent from school have more problems. Attrition due to refusal to participate was very low in the present study.

Second, the design in the study is cross-sectional and no conclusions about causality may be drawn; a longitudinal design would have strengthened the conclusions drawn from comparisons between the boys and girls. Also the group is rather homogenous in age and the results for boys might be different if older adolescents had been studied. There may also be some effects of deviations from normality for some of the variables and of collinearity. However, as pointed out by Howell (2007), rather substantial departures from normality might be tolerable and the tolerance levels found did not indicate large problems with collinearity.

A more nuanced description of the relations between different aspects of the selfconcept and aspects of mental health has implications for the assessment of and intervention in mental health problems in adolescence. It suggests that treatment and as- 
sessment should be more gender specific with more focus on a negative way of treating and evaluating self for girls while for boys negative images of early parental behaviour should be more in focus. Future research should focus on gender-specific vulnerability, girls' low self-affirmation and high self-blame, and boys' self-neglect in order to develop a better understanding of the factors related to mental health problems in adolescents.

Conclusions: The main results support the value of a multidimensional perspective on the self-concept for exploring and understanding the complexity of mental health problems. The results also emphasise the importance of accounting for genderspecific patterns of aspects of the self-concept in relation to the internalising and externalising of problems.

\section{References}

ACHenBach, T.M. (1991) Manual for the Youth Self-Report and 1991 Profile (Burlington: University of Vermont).

ADAMSON, L. \& B. LyXELL (1996) 'Self-Concept and Questions of Life: Identity Development during Late Adolescence', Journal of Adolescence 6, 569-82.

Aluja, A., V. Del BARrio \& L.F. GARCÍA (2005) 'Relationships between Adolescents' Memory of Parental Rearing Styles, Social Values and Socialisation Behavior Traits', Personality and Individual Differences 39, 903-12.

Andersen, B., J.C. LAVoIE \& C.S. DunKel (2007) 'Individuation and Parents as People: Measurement Concerns Regarding two Aspects of Autonomy', Journal of Adolescence 5, 751-60.

Armelius, K. \& Å. GranBerg (2000) 'Self-Image and Perception of Mother and Father in Psychotic and Borderline Patients', Psychotherapy Research 10, 147-58.

ARMELIUS, B.-Å. \& B. HÄGGLÖF (1998) Psykiska störningar hos ungdomar med sociala problem (Umeå: Universitet Umeå, Institutionen för Psykologi).

Belter, R.W., K.Y. FosTeR, \& P.S. IMM (1996) 'Convergent Validity of Selected Scales of MMPI and the Achenbach Child Behaviour Checklist-Youth Self-Report', Psychological Reports 79, 1091-100.

Benjamin, L.S. (1974) 'Structural Analysis of Social Behavior' Psychological Review 81, 392-425.

BENJAMIN, L.S. (1987) SASB Short Form User's Manual (Salt Lake City: Intrex Interpersonal).

BENJAmin, L.S. (1993) Interpersonal Diagnosis and Treatment of Personality Disorders (New York: Guilford).

BENJAMIN, L.S. (1996) 'A Clinician-Friendly Version of the Interpersonal Circumplex: Structural Analysis of Social Behavior (SASB)', Journal of Personality Assessment 66, 248 66.

Bowlby, J. (1988) A Secure Base: Parent-Child Attachment and Healthy Human Development (New York: Basic Books).

Broberg, A.G., K. Ekeroth, P.A. Gustafsson, K. Hansson, B. HägglöF, T. Ivarsson \& B. LARSSON (2001) 'Self-Reported Competencies and Problems among Swedish Adolescents: A Normative Study of the YSR', European Child and Adolescent Psychiatry 10, 186-93. 
ButLeR, J.R. \& S.L. GASSON (2005) 'Self-Esteem/Self-Concept Scales for Children and Adolescents: A Review', Child and Adolescent Mental Health 10, 190-201.

CHodorow, N. (1978) The Reproduction of Mothering (Los Angeles: U of California P).

EBERHART, N.K., J.H. SHIH, C.L. HAMMEN \& P.A. BRENNAN (2006) 'Understanding the Sex Differences in Vulnerability to Adolescent Depression: An Examination of Child and Parent Characteristics', Journal of Abnormal Child Psychology 34, 493-506.

ERICKSON, T.M. \& A.L. PINCUS (2005) 'Using Structural Analysis of Social Behaviour (SASB) Measures of Self- and Social Perception to Give Interpersonal Meaning to Symptoms: Anxiety as an Exemplar', Assessment 12, 243-54.

ERKolahti, R., T. Ilonen, S. SAARIJÄRVI \& P. Terho (2003) 'Self-Image and Depressive Symptoms among Adolescents in a Non-Clinical Sample', Nordic Journal of Psychiatry $57,447-51$.

FLORSHEIM, P., W.P. HENRY \& L.S. BENJAMIN (1996) 'Integrating Individual and Interpersonal Approaches to Diagnosis: The Structural Analysis of Social Behavior and Attachment Theory' in F.W. KASLOW, ed., Handbook of Relational Diagnosis and Dysfunctional Family Patterns (New York: John Wiley) 81-101.

GILligan, C. (1982) In a Different Voice (Cambridge: Harvard UP).

Gramzow, R.H., A.J. ElLIOT, E. ASHER \& H.A. MCGREgOR (2003) 'Self-Evaluation Bias and Academic Performance: Some Ways and Some Reasons Why', Journal of Research in Personality 37, 41-61.

HARTER, S., S. Bresnick, H.A. Bouchey \& N.R. WhiteSElll (1997) 'The Development of Multiple Role-Related Selves During Adolescence', Development and Psychopathology $9,835-53$.

HAY, I. (2000) 'Gender Self-Concept Profiles of Adolescents Suspended from High School', Journal of Child Psychology and Psychiatry 41, 345-52.

Hope, T.L., C. AdAms, L. Reynolds, D. Powers, R.A. Perez \& M.L. Kelly (1999) 'Parent vs. Self-Report: Contributions toward Diagnosis of Adolescent Psychopathology', Journal of Psychopathology and Behavioural Assessment 21, 349-63.

Howell, D.C. (2007) Statistical Methods for Psychology $\left(6^{\text {th }}\right.$ ed.; Belmont, CA: Thomson Wadsworth).

Hudson, J.L. \& R.M. RAPEE (2001) 'Parent-Child Interactions and Anxiety Disorders: An Observational Study', Behaviour Research and Therapy 39, 1411-27.

HuMPHREY, L.L. (1989) 'Observed Family Interactions Among Subtypes of Eating Disorders Using Structural Analysis of Social Behavior', Journal of Consulting and Clinical Psychology $57,206-14$.

KIESLER, D.J. (1996) Contemporary Interpersonal Theory and Research: Personality, Psychopathology, and Psychotherapy (New York: John Wiley).

Leadbeater, B.J., G.P. Kupermine, S.J. Blatt \& C. Hertzog (1999) 'A Multivariate Model of Gender Differences in Adolescents' Internalizing and Externalizing Problems', Developmental Psychology 35, 1268-82.

MARSh, H.W., R.H. PARADA, \& V. AYOTTE (2004) 'A Multidimensional Perspective of Relations between Self-Concept (Self Description Questionnaire II) and Adolescent Mental Health (Youth Self-Report)', Psychological Assessment 16, 27-41.

MARSH, H.W., R.H. PARADA, A.S. YeUnG \& J. HEALEY (2001) 'Aggressive Troublemakers and Victims: A Longitudinal Model Examining the Pivotal Role of Self-Concept', Journal of Educational Psychology 2, 411-19.

McCullough, G., E.S. Huebner, \& J.E. Laughlin (2000) 'Life Events, Self-Concept, and Adolescents' Positive Subjective Well-Being', Psychology in the Schools 37 (3), 281-90. 
Meadows, S.O., J.S. Brown \& G.H. Elder (2006) 'Depressive Symptoms, Stress, and Support: Gender Trajectories from Adolescence to Young Adulthood', Journal of Youth and Adolescence 35, 89-99.

Meeus, W., J. IEdema, G. MAassen \& R. Engels (2005) 'Separation-Individuation Revisited: On the Interplay of Parent-Adolescent Relations, Identity and Emotional Adjustment in Adolescence', Journal of Adolescence 1, 89-106.

MoRETTI, M.M., R. HOLLAND, \& S. MCKAY (2001) 'Self-Other Representations and Relational and Overt Aggression in Adolescent Girls and Boys', Behavioral Science and the Law 19, 109-26.

Muris, P., C. MeEsters \& S.VD. Berg (2003) 'Internalising and Externalising Problems as Correlates of Self-Reported Attachment Style and Perceived Parental Rearing in Normal Adolescents', Journal of Child and Family Studies 12, 171-83.

Noom, M. J., M. Dekovic \& W.H.J. MeEus (1999) 'Autonomy, Attachment and Psychosocial Adjustment during Adolescence: A Double-Edged Sword?', Journal of Adolescence 6, 771-83.

Noom, M.J., M. Dekovic \& W.H.J. MeEus (2001) 'Conceptual Analysis and Measurement of Adolescent Autonomy', Journal of Youth and Adolescence 30, 577-95.

Orbach, I., M. Mikulincer, D. Stein \& O. COHEN (1998) 'Self-Representation of Suicidal Adolescents', Journal of Abnormal Psychology 107, 435-39.

ÖSTGÅRD-YBRANDT, H. \& B.-Å. ARMELIUS (2004) 'Self-Concept and Perception of Early Mother and Father Behaviour in Normal and Antisocial Adolescents', Scandinavian Journal of Psychology 45, 437-47.

Pincus, A.L., M.B. GuRTMAN \& M.A. RuIZ (1998) 'Structural Analysis of Social Behavior (SASB): Circumplex Analyses and Structural Relations with the Interpersonal Circle, and the Five-Factor Model of Personality', Journal of Personality and Social Psychology 74, $1629-45$.

Prinstein, M.J., J.L. Borelli, C.S.L. CheAH, V.A. SimON \& J.W. Aikins (2005) 'Adolescent Girls' Interpersonal Vulnerability to Depressive Symptoms: A Longitudinal Examination of Reassurance-Seeking and Peer Relationships', Journal of Abnormal Psychology 114, 676-88.

Roelofs, J., C. Meesters, M. Huurne, L. Bamelius \& P. Muris (2006) 'On the Links between Attachment Style, Parental Rearing Behaviors, and Internalizing and Externalizing Problems in Non-Clinical Children', Journal of Child and Family Studies 15, 331-44.

RuchKIN, V.V., R.A. Koposov, M. EISEMANN \& B. HÄGGLÖF (2001) 'Conduct Problems in Russian Adolescents: The Role of Personality and Parental Rearing', European Child and Adolescent Psychiatry 10, 19-27.

RudolPh, K.D. \& C.S. Conley (2005) 'The Socioemotional Costs and Benefits of SocialEvaluative Concerns: Do Girls Care too Much?', Journal of Personality 73, 115-37.

RudolPh, K.D. \& C. HAMmen (1999) 'Age/Gender as Determinants of Stress Exposure, Generation, and Reactions in Youngsters: A Transactional Perspective', Child Development $70,660-77$.

RYAN, R.M. \& J.H. LYNCH (1989) 'Emotional Autonomy Versus Detachment: Revisiting the Vicissitudes of Adolescence and Young Adulthood', Child Development 60, 340-56.

Silk, S.S., A.S. Morris, T. KAnAYA \& L. SteInBerg (2003) 'Psychological Control and Autonomy Granting: Opposite Ends of a Continuum or Distinct Constructs?', Journal of Research on Adolescence 13, 113-28. 
Siqueland, L., P.C. Kendall \& L. SteinBerg (1996) 'Anxiety in Children: Perceived Family Environments and Observed Family Interaction', Journal of Clinical Child Psychology 25, 225-37.

Song, L., J. Singh \& M. Singer (1994) 'The Youth Self-Report Inventory: A Study of its Measurement Fidelity', Psychological Assessment 6, 236-45.

Statistics Sweden (2001) Official Statistics of Sweden: Up to 18. Facts about Children and Youth (Örebro: SCB-Tryck).

SteinberG, L. (2000) 'The Family at Adolescence: Transition and Transformation', Journal of Adolescent Health 3, 170-78.

SteInBERG, L. \& A. SHEFFIELD Morris (2001) 'Adolescent Development', Annual Review of Psychology 52, 83-110.

Steinberg, L., I. Blatt-Eisengart \& E. CAuffman (2006) 'Patterns of Competence and Adjustment Among Adolescents from Authoritative, Authoritarian, Indulgent, and Neglectful Homes: A Replication in a Sample of Serious Juvenile Offenders', Journal of Research on Adolescence 16, 47-58.

STERN, D. (1985) The Interpersonal World of the Infant: A View from Psychoanalysis and Developmental Psychology (New York: Basic Books).

Verhulst, F.C., T.M. Achenbach, J.vd. Ende, N. Erol, M.C. LAmbert, P.W.L. Leung, M.A. SilviA, N. ZiBER \& S.R. ZUBRICK (2003) 'Comparison of Problems Reported by Youths from Seven Countries’, American Journal of Psychiatry 160, 1479-85.

WELZENIS, I.V. (1997) 'The Self-Concept of Societally Vulnerable, and Delinquent Boys within the Context of School and Leisure Activities', Journal of Adolescence 6, 695-705.

Wenar, C. \& P. Kerig (2000) Developmental Psychopathology: From Infancy Through Adolescence (4th ed.; New York: McGraw-Hill).

Wonderlich, S., M.H. KleIn \& J.R COUNCIL (1996) 'Relationship of Social Perceptions and Self-Concept in Bulimia Nervosa', Journal of Consulting and Clinical Psychology 64, $1231-37$. 